\title{
The Effect of Sexual Counseling Based on PLISSIT Model on Sexual Function of Pregnant Women: A Randomized Controlled Clinical Trial
}

\author{
Zhila Shahbazi $^{\mathbb{1}}$, Azizeh Farshbaf-Khalili² $^{2}$ Niloofar Sattarzadeh ${ }^{3}$, Mahin Kamalifard $^{*}{ }^{(\mathbb{D}}$
}

\begin{abstract}
Objectives: Several factors, including pregnancy which is associated with physical, psychological, and hormonal changes, affect females and their sexual partners' relation and function. This study aimed to investigate the effect of "permission, limited information, specific suggestions, intensive therapy" (PLISSIT)-based sexual counseling on the sexual function of pregnant women.

Materials and Methods: The present randomized controlled trial was performed on 70 pregnant women who had a sexual function score of less than the cut-off point within a gestation period of 16-20 weeks. The participants were randomly divided into intervention and control groups by the blocking method. The intervention group received individual counseling based on the PLISSIT model by a well-trained midwife while the control group only received the usual care for pregnancy. The primary outcome measures were the total score of female sexual function four weeks after the intervention. Finally, the data were collected using a questionnaire of personal and midwifery information, as well as the female sexual function index in previous stages and four weeks after the intervention. All analyses were based on the intention to treat the approach.

Results: There was a significant difference between the mean total score of sexual function (adjusted mean difference: 9.07; 95\% CI: 7.24 to 10.90) and all the sub-scales that intervention and control groups adjusted for baseline scores four weeks after the intervention $(P<0.05)$. Consultation significantly reduced the frequency of sexual dysfunction and there was a significant difference between the 2 groups in this regard $(P<0.001)$.

Conclusions: Given the effect of sexual counseling on the improvement of sexual function of pregnant women based on the PLISSIT model, this approach is recommended during pregnancy.

Keywords: Sexual Dysfunction, Pregnancy, Counseling, PLISSIT Model
\end{abstract}

\section{Introduction}

Sexual instinct is one of the strongest instincts of the human that affects the person's behavior (1), as well as individual and social life (2). Sexual health includes sexual development, reproductive health, along with the ability to create and maintain meaningful interpersonal relationships (3). In addition, sexual function is an important part of health and an integral part of life which leads to well-being and high quality of life (4). Conversely, sexual dysfunction is defined as the presence of any problem in an individual or a couple during sexual activity, including desire, lubrication, arousal, and orgasm (5). Several parameters such as hormonal changes, menses, pregnancy, childbirth, lactation, and menopause affect sexual function (6).

During pregnancy, the sexuality and function of pregnant women and their spouses are unpredictable and may increase, decrease, or remain unchanged (7). According to the studies conducted in different countries, sexual dysfunction is reported between $23.4 \%$ and $70 \%$ during the different trimesters of pregnancy (8-10). This is due to an injury to the fetus, bleeding, infection, the premature rupture of membrane, abortion, preterm labor, physical discomfort, concern for the inappropriate position of sexual intercourse, the feelings of guilt, the feelings of diminished sexual attractiveness, and improper self-image $(1,8,10-12)$.

Sexual relationships during pregnancy can increase commitment, trust, love, intimacy, emotional communication between the couples and satisfaction with the marital relationship $(13,14)$. Further, sexual function and satisfaction are important factors which affect health and life satisfaction (15). On the other hand, sexual dysfunction may lead to depression in individuals (16), interpersonal problems, marital discord, and divorce and thus decrease the quality of life (17).

Accordingly, providing correct and scientific information about physical and mental changes during pregnancy by health care providers, especially midwives, along with sexual counseling is very helpful in prenatal 
education (18).

There are several frameworks to help health care providers implement an effective and appropriate strategy for solving sexual problems. Permission, limited information, specific suggestions, intensive therapy (PLISSIT) model is one of the most used models in sexual counseling and assessment $(19,20)$.

Regarding the results of the above-mentioned studies and the effect of the knowledge, attitude, values, and cultural differences on sexual function $(21,22)$ and the lack of similar intervention studies, especially evaluating the effectiveness of the counseling PLISSIT model on pregnant women's sexual function in our region, the current study sought to review the effect of sexual counseling based on this model on the sexual function of pregnant women.

\section{Methods}

Study Design and Participants

This study was a randomized controlled clinical trial (2017) with a parallel-arm design which was performed on 70 eligible pregnant women within 18 to 35 years old in Ardebil, Iran. They were selected by the convenience sampling method and equally categorized into intervention and control groups each containing 35 cases.

The inclusion criteria were being pregnant at the gestational age of 16 to 20 weeks, having a health record in Ardebil health centers, having a sexual function score below 28 , being literate enough to read and write, and being married to one spouse $(10,23)$.

On the other hand, the exclusion criteria included the prohibition of sexual activity for medical reasons, addiction or alcohol abuse, participation in other similar studies, and the occurrence of a horrible incident (e.g., the death or acute illness of close relatives) within three months before the study.

The primary outcome measures were the general mean score of female sexual function. Four weeks after the intervention while the secondary outcome parameters encompassed the mean score of desire, arousal, lubrication, orgasm, satisfaction, and the pain sub-scales of sexual function, along with the frequency of sexual dysfunction four weeks after the end of the intervention. Furthermore, the sample size was based on the study by Rostamkhani et al (24) that evaluated the sexual function of pregnant women, taking into account the measures as $\mathrm{m}_{1}=24.76$, $\mathrm{m}_{2}=28.12, \quad \mathrm{SD}_{2}=4.36, \quad \mathrm{SD}_{1}=4.50$, and power $=90 \%$. Accordingly, 35 women were assigned to each group while considering $20 \%$ plausible dropout.

\section{Sampling}

The sampling was initiated once the study was confirmed by the Ethics Committee of Tabriz University of Medical Sciences (IR.TBZMED.REC.1395.1311) and registered at the Iranian Register Center for Clinical Trials (identifier: IRCT201505246582N14; https://www.irct.ir/trial/7043). First, 5 centers were randomly selected from among 16 health centers in Ardebil (Iran) and then 14 individuals were selected from each center using a convenience sampling technique. The researcher selected eligible individuals with a score below 28 in the Sexual Function Questionnaire and then explained the study objectives and procedure asking them to participate in the study. Sampling continued in each center until the completion of the sample size. The written consent form was obtained from women before conducting the study.

\section{Randomization and Intervention}

Pregnant women were selected by using a randomized block design with blocks of size 4 and 6, and an allocation ratio of 1:1 through random allocation software and the participants were divided into receiving sexual counseling and control groups. The randomized allocation sequence was generated by a person not involved in the research. In order to conceal the allocation, the type of intervention was written in the paper by the same individual based on the random allocation sequence and placed in identical, opaque, and closed envelopes which numbered from 1 to 70, respectively. Accordingly, 14 consecutive envelopes from 1 to 70 were randomly assigned to each center. The first envelope was given to the first person who was eligible to enter the study. This was continued until the samples were completed. Meanwhile, the participant, the researcher, and the statistical analyst were unaware of the content of envelopes (allocation concealment). However, after the random allocation of the individual to the groups, it was impossible to blind the researcher and the participant in terms of the type of intervention.

Both groups completed the demographic characteristics and sexual function questionnaire (FSFI, Female Sexual Function Index) before the intervention.

In the intervention group, individual and face-toface counseling was performed in the counseling room, which was a quiet and bright room with a dimension of approximately $3 * 4$ meters and suitable for counseling. Depending on the needs of the participants, each counseling session lasted 45-60 minutes, held per week for consecutive weeks (1-4 sessions), and was based on the PLISSIT model $(25,26)$. Table 1 demonstrates data in this regard.

The control group also received routine pregnancy care. The researcher gave the participants a phone number so that they can call and ask their questions. Once the research was completed, the control group also received corporation counseling in order to tackle their problems.

\section{Assessment of Study Variables}

The data collection instruments included a history of pregnancy and a demographic questionnaire and a sexual function index questionnaire (FSFI). The validity of the demographic questionnaire and the history of pregnancy were confirmed by 10 faculty members. This questionnaire was completed at the beginning of the inclusion process 
Table 1. PLISSIT Model of Sexual Counselling

\begin{tabular}{ll}
\hline Levels of the model & $\begin{array}{l}\text { After obtaining the permission of the pregnant woman, the counselor attempts to introduce the subject and sexual } \\
\text { orientation. He/She begins discussing the sexual issues, providing an appropriate condition for sexual counseling } \\
\text { in a safe environment, and maintaining the willingness to collaborate with the women with an unconditional and } \\
\text { unobtrusive attitude in an open dialogue. At this step, the participants are given time to talk about their sexual } \\
\text { problems and concerns during pregnancy. }\end{array}$ \\
Limited Information (LI) & $\begin{array}{l}\text { Limited information about the changes, orientations, problems, and concerns of the first step is provided directly } \\
\text { and reliably. }\end{array}$ \\
Specific Suggestions (SS) & $\begin{array}{l}\text { Specific and unique suggestions for sexual relations; At this step, depending on the type of the problem or } \\
\text { particular concern, a solution is provided. }\end{array}$ \\
Intensive therapy (IT) & $\begin{array}{l}\text { Intensive care and, if necessary, referral to a psychologist, psychiatrist or social worker is recommended, especially } \\
\text { when the midwife is not able to address the issues or problems. In order to help the mother and solve her } \\
\text { problem, she is referred to the specialists. }\end{array}$ \\
\hline
\end{tabular}

before assigning the women to study groups.

Moreover, FSFI was used to measure the sexual function of pregnant women. This questionnaire contained 19 questions including 6 variables of desire, arousal, lubrication, orgasm, satisfaction, and sexual pain. The desire score was 1-5 while the sexual arousal, vaginal lubrication, orgasm, and pain were given score 0-5. Finally, the sexual satisfaction score was 0 (or 1)-5. A zero score indicated that the person had no sexual activity over the past four weeks.

According to the instruction of the questionnaire designer, the score was obtained by accumulating the scores in each of the 6 variables. Thus, a higher score suggested a better sexual function. According to the weights of the variables, the maximum score was 6 and 36 for each variable and the whole scale. Conversely, the minimum score was 1.2 for the sexual desire while the sexual arousal, vaginal lubrication, orgasm, and pain were estimated to be zero. Additionally, satisfaction had a score of 0.8 and the lowest and highest scores for the entire scale were 2 and 36, respectively. Similarly, the cut-off point was $28,3.3,3.4,3.4,3.8$, and 3.8 for the whole scale, desire, lubrication, orgasm, satisfaction, and pain, respectively, and the scores above the cut-off point suggested good sexual function (27). The validity of this questionnaire was confirmed by Fakhri et al in Iran (23). In the present study, the reliability of this questionnaire was investigated by studying 20 pregnant women and determining the internal stability and the Cronbach alpha was estimated at 0.91 . Moreover, having performed a posttest on 20 pregnant women with a 15-day interval, the correlation coefficient (infraclass correlation coefficient) was determined with a 95\% CI 0.962 (0.938-0.985).

Finally, both groups completed the post-test questionnaires four weeks after the last consultation.

\section{Statistical Analysis}

Data were analyzed using SPSS, version 22. In addition, the Kolmogorov-Smirnov test was used to evaluate the normal distribution of variables, the general score of sexual function, and its 6 variables before and after the intervention. All the variables were normally distributed before and after the intervention except for the baseline sexual arousal. Further, the independent $t$ test was utilized before the intervention in order to compare the general sexual function score and its sub-scales. Furthermore, the Mann-Whitney test was employed to compare sexual arousal, followed by applying ANOVA test to compare the sexual function score and its sub-scales between the groups after the intervention. Meanwhile, intra-group sexual function score was compared before and after the intervention using the paired $t$ test. Eventually, the chisquare, Mann-Whitney, and Fisher exact tests were used to compare the groups in terms of demographic and history variables. All analyses were based on the Intention-tothreat approach and $P<0.05$ was regarded as statistically significant.

\section{Results}

In this study, 1086 pregnant women were evaluated based on the study criteria. Finally, 70 pregnant women entered the study and randomly assigned into 2 intervention and control groups each containing 35 individuals. Two participants in the intervention group were excluded due to immigration and the husband's dissatisfaction. Finally, 68 women were analyzed based on the aim of the study (Figure 1). According to the results of this study, the participants of the 2 groups were not significantly different in terms of demographic and midwifery characteristics $(P<0.05)$, the details of whom are provided in Table 2 .

The mean (SD) age of the participants was 25.7 (4.6) years old in the counseling group while it was 27.54 (3.95) in the control group. Nearly half of the women in both groups had a university education, and $57.1 \%$ and $71.4 \%$ became pregnant with prior planning in counseling and control groups, respectively. About two-thirds of women in both groups were pregnant in the first abdomen.

Moreover, more than three-quarters of the participants 


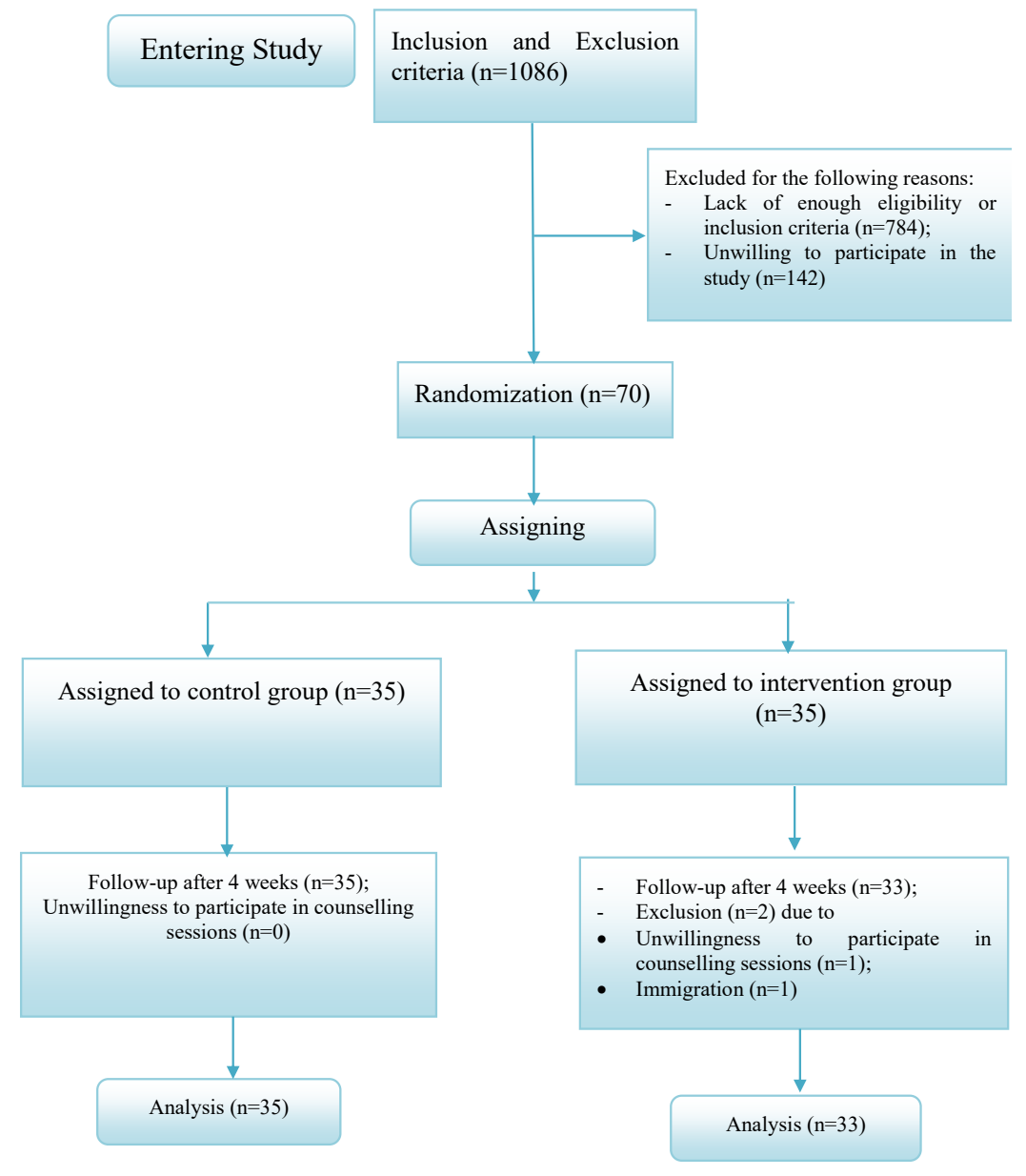

Figure 1. The Flowchart of Participants.

in both groups were housewives, and the majority of them had sufficient incomes. Finally, about two-thirds of the women received no prior education or counseling about sexual relations during pregnancy.

Before the intervention, all participants of both groups had sexual dysfunction while there was a significant difference between the groups in terms of the overall score of sexual function $(P=0.032)$, as well as orgasm $(P=0.048)$, sexual satisfaction $(P=0.027)$, and sexual pain $(P=0.044)$ sub-scales. However, no significant difference was observed between sexual desire $(P=0.421)$, sexual arousal $(P=0.432)$, and lubrication $(P=0.327)$. Conversely, the mean score of the overall sexual function in the intervention group changed from 19.30 (5.82) before the intervention to 29.88 (3.16) within four weeks after the intervention (mean difference [MD]: 10.54, CI 95\%: 8.07 to 13.02 ), which was statistically significant. However, the mean score of the overall sexual function in the control group demonstrated a reduction from 22.12 (4.95) before the intervention to 21.79 (4.89) within four weeks after the intervention (MD: -0.24 , CI 95\%: -0.84 to $0.35)$, the related data are shown in Table 3, Table 4 and Figure 2.

Based on the results of the ANOVA test, the mean score of the overall sexual function of the intervention group was compared with that of the control group. A significant difference was found between the mean general score of sexual function (adjusted MD: 9.07, CI 95\%: 7.24 to 10.90) and all the sub-domains in the intervention and control groups four weeks after the intervention $(P<0.05)$. In other words, the mean score of sexual function and all its variables in the counseling group was higher than the cutoff point after counseling (Table 4).

Before entering the study, sexual dysfunction was $100 \%$ in both intervention and control groups. However, four weeks after the intervention, it reached $24.3 \%$ and $97.1 \%$ in the intervention and control groups, respectively, which was statistically significant $(P<0.001)$. Tables 2 and 3 represent the related data in this respect.

\section{Discussion}

According to previous research, the majority of women are susceptible to sexual dysfunction during pregnancy due to the fear of injury to the fetus, female reduced sexual attractiveness (11), the woman's negative image of herself, concerns about abortion, physical discomfort (28), and partner's reduced desire (29). Additionally, sexual dysfunction during pregnancy causes depression, sexual 
Table 2. The Individual and Social Characteristics and Midwifery in the Groups Under Study

\begin{tabular}{|c|c|c|c|}
\hline Characteristics & $\begin{array}{l}\text { Counseling } \\
\text { Group }(n=35)\end{array}$ & $\begin{array}{l}\text { Control Group } \\
\qquad(n=35)\end{array}$ & $P$ Value \\
\hline \multicolumn{4}{|l|}{ Age (year) ${ }^{*}$} \\
\hline Mean (SD) & 25.74 (4.59) & $27.54(3.95)$ & $0.083^{\mathrm{a}}$ \\
\hline \multicolumn{4}{|l|}{ Weight $(\mathrm{kg})^{*}$} \\
\hline Mean (SD) & $67.8(10.61)$ & $66.34(9.76)$ & $0.552^{\mathrm{a}}$ \\
\hline \multicolumn{4}{|c|}{ Duration of marriage ${ }^{*}$ (mon) } \\
\hline Mean (SD) & $53.97(41)$ & $47.84(47.6)$ & $0.327^{b}$ \\
\hline \multicolumn{4}{|l|}{ Education } \\
\hline Primary & $2(5.7)$ & $2(5.7)$ & \multirow{4}{*}{$0.905^{d}$} \\
\hline Secondary & $7(20)$ & $7(20)$ & \\
\hline High school \& diploma & $11(31.4)$ & $9(25.7)$ & \\
\hline University & $15(42.8)$ & $17(48.6)$ & \\
\hline \multicolumn{4}{|l|}{ Income } \\
\hline Just sufficient & $20(57.1)$ & $28(80)$ & \multirow{2}{*}{$0.070^{d}$} \\
\hline Not sufficient & $15(42.9)$ & $7(20)$ & \\
\hline \multicolumn{4}{|l|}{ Job } \\
\hline Housewife & $27(77.1)$ & $28(80)$ & \multirow{4}{*}{$0.096^{c}$} \\
\hline Employee & $5(14.3)$ & $2(5.7)$ & \\
\hline Free & 0 & $4(11.4)$ & \\
\hline Others & $3(8.6)$ & $1(2.9)$ & \\
\hline \multicolumn{4}{|l|}{ The type of pregnancy } \\
\hline Planned & $20(57.1)$ & $25(71.4)$ & \multirow[t]{2}{*}{$0.318^{\mathrm{e}}$} \\
\hline Unplanned & 15 (42.9) & $10(27.6)$ & \\
\hline \multicolumn{4}{|l|}{ Contraception } \\
\hline Tablet & $5(14.3)$ & $4(11.4)$ & \multirow[t]{6}{*}{$0.553^{c}$} \\
\hline Condom & $2(5.7)$ & $3(8.6)$ & \\
\hline IUD & 0 & $2(5.7)$ & \\
\hline Withdrawal & $17(48.6)$ & $13(37.1)$ & \\
\hline Rhythmic & 0 & $2(5.7)$ & \\
\hline No prevention & $11(31.4)$ & $11(31.4)$ & \\
\hline \multicolumn{4}{|c|}{ Sexual education in pregnancy } \\
\hline Yes & $11(31.4)$ & $13(37.1)$ & \multirow[t]{2}{*}{$0.801^{\mathrm{e}}$} \\
\hline No & $24(68.6)$ & 22 (62.9) & \\
\hline
\end{tabular}

All the numbers are shown as frequency (\%) except for variables that are indicated with the sign*.

${ }^{\mathrm{a}}$ Independent $t$ test, ${ }^{\mathrm{b}}$ Mann-Whitney test; ${ }^{\mathrm{c}}$ Fisher exact test; ${ }^{\mathrm{d}} \chi^{2}$ for trend; ${ }^{e} \chi^{2}$. dissatisfaction, and marital distress, postpartum sexual dysfunction, along with the husband's sexual betrayal $(16,30,31)$. During a natural pregnancy, there is no ban on sexual and vaginal intercourse instead the couple maintains their interactions and sexual relationships which can improve their intimacy and health and deepen their relationship $(14,31)$.

The present study was a randomized controlled clinical trial which sought to evaluate the effect of counseling on the sexual function of pregnant women based on the PLISSIT model. The results showed that PLISSITbased counseling reduced the sexual problems while it significantly increased the sexual function and its 6-dimensional domains in pregnant women compared to the control group.

The comparison of sexual function before and after counseling intervention in both intervention and control groups indicated that the mean total score of sexual function in the counseling group increased significantly with no significant difference in the control group. By adjusting the effect of the score before the intervention, there was a significant difference in the total score of sexual function and all its sub-scales in the 2 groups four weeks after the intervention.

Before entering the study, the sexual dysfunction was $100 \%$ in both intervention and control groups. However, four weeks after the intervention, it reached $24.3 \%$ and $97.1 \%$ in the intervention and control groups, respectively, which was statistically significant.

Various studies evaluated the impact of the PLISSIT model on the sexual performance of women. For example, Rostamkhani et al (24) conducted a quasi-experimental study on 80 women who married under 30 and had sexual problems based on their own confession during a 2-hour counseling session held based on the PLISSIT model. Using the female sexual function index, they found a significant increase in the mean total sexual function and its 6 sub-scales in the consulting group as compared to the control group $(P<0.001)$. The results of this study are consistent with the findings of the present study regarding

Table 3. Comparison of the General Means (SD) Score of Sexual Function and Its Dimensions Among the Groups at Baseline

\begin{tabular}{|c|c|c|c|}
\hline Components & Counseling Group ( $n=35)$ & Control Group $(n=35)$ & $P$ Value \\
\hline Total score & $19.30(5.82)$ & $22.12(4.95)$ & $0.032^{\mathrm{a}}$ \\
\hline Sexual desire & $3.46(1.16)$ & $3.27(0.7)$ & $0.421^{\mathrm{a}}$ \\
\hline Sexual arousal & $2.84(1.51)$ & $3.24(1.09)$ & $0.432^{b}$ \\
\hline Lubrication & $3.59(1.83)$ & $3.96(1.31)$ & $0.327^{\mathrm{a}}$ \\
\hline Orgasm & $2.91(1.70)$ & $3.66(1.40)$ & $0048^{a}$ \\
\hline Sexual satisfaction & $4.10(1.05)$ & $4.66(1.01)$ & $0.027^{a}$ \\
\hline Pain during sexual intercourse & $2.38(1.98)$ & $3.31(1.78)$ & $0.044^{\mathrm{a}}$ \\
\hline Dysfunction frequency (score $<28$ ) & $100(35)$ & $100(35)$ & 1.00 \\
\hline
\end{tabular}

Note. Dysfunction frequency is reported in number (\%). In addition, the range of variations for the subscales of desire, satisfaction, the remainder of the subscales, and the total function is 1.2-6, 0.8-6, 0-6, and 2-36, respectively. The higher scores represent better sexual function as well. Further, the cut-off points for the whole scale, desire, lubrication, orgasm, satisfaction, and sexual pain are $28,3.3,3.4,3.4,3.8$, and 3.8, respectively. andependent t-test, ${ }^{\mathrm{b}}$ Mann-Whitney test. 
Table 4. Comparison of General Means (SD) Score of Sexual Function and Its Dimensions in the Groups Four Weeks After the End of Intervention

\begin{tabular}{|c|c|c|c|c|}
\hline Components & Counseling Group $(n=35)$ & Control Group ( $n=35)$ & Adjusted MD $(95 \% \mathrm{Cl})^{a}$ & $P$ Value $^{\text {b }}$ \\
\hline Total score & $29.80(3.16)$ & $21.79(4.89)$ & 9.07 (7.24-10.90) & $<0.001$ \\
\hline Sexual desire & $4.29(0.85)$ & $3.22(0.78)$ & $0.94(0.61-1.28)$ & $<0.001$ \\
\hline Sexual arousal & $4.51(0.70)$ & 3.09 (1.07) & $1.42(0.97-1.86)$ & $<0.001$ \\
\hline Lubrication & $5.55(0.37)$ & $4.13(1.36)$ & 1.50 (1.05-1.95) & $<0.001$ \\
\hline Orgasm & $5.01(0.87)$ & $3.61(1.21)$ & 1.74 (1.29-2.19) & $<0.001$ \\
\hline Sexual Satisfaction & $5.30(0.71)$ & $4.47(0.87)$ & $1.12(0.82-1.42)$ & $<0.001$ \\
\hline Pain & $5.11(0.73)$ & $3.24(.68)$ & $2.15(1.58-2.71)$ & $<0.001$ \\
\hline Dysfunction frequency $(<28)$ & $8(24.3)$ & $33(97.1)$ & & $<0.001$ \\
\hline
\end{tabular}

MD: Mean difference.

a Analysis of covariance adjusted for baseline values.

The range of variations for the subscales of willingness, satisfaction, the remainder of the subscales, and the total function is $1.2-6,0.8-6,0-6$, and 2-36, respectively. In addition, the cut-off points for the whole score, desire, lubrication, orgasm, satisfaction, and sexual pain are $28,3.3,3.4,3.4,3.8$, and 3.8 , respectively.

improving the sexual function and all of its domains in pregnant women.

Similarly, Rutte et al performed a clinical trial on 130 subjects (40-75 year-old women and men) with type 2 diabetes who were dissatisfied with their sexual function. The counseling was conducted based on the PLISSIT model. Telephone follow-up, 3 and 12 months after the intervention showed improved sexual function, sexual satisfaction, and the quality of life in the intervention group. The results of the above-mentioned study corroborate with the results of the present study in terms of improving the sexual function of pregnant women (32).

Another clinical trial was performed by Farnam et al on 84 women aged 20-52 with sexual problems who referred to sexual counseling clinic The participants were counselled and trained based on PLISSIT model and sexual health model (SHM), respectively. The sevenmonth follow-up demonstrated a significant increase $(P<0.001)$ in the mean score of arousal, orgasms, sexual satisfaction, and total sexual function score in PLISSITbased counseling group (from 25.8 to 32.9 ) compared to SHM-based training group (from 28.5 to 32.8 ), which is in line with the results of this study. However, the increase in

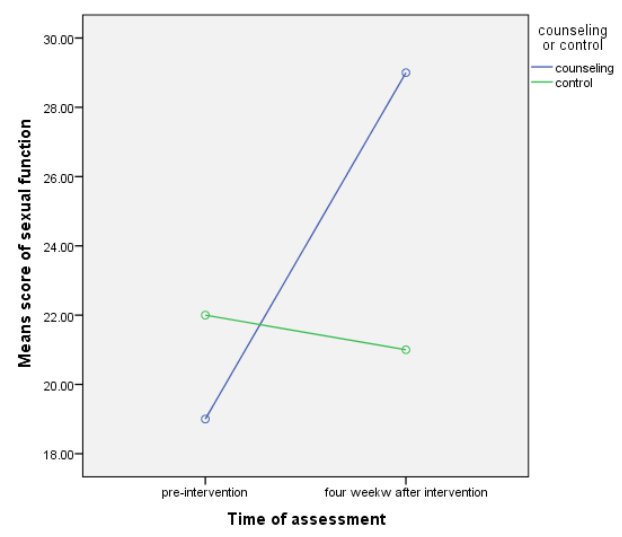

Figure 2. The Mean Sexual Function Score Before the Intervention and 4 Weeks After the Intervention in the Study Groups. sexual desire score was not statistically significant in their study (33). Therefore, the present study seems not to be in conformity with the above-mentioned study as regards the desire sub-scale because our study was conducted during pregnancy and the reduced sexual desire in pregnancy can be attributed to inappropriate and temporary attitudes and beliefs. Accordingly, changes in attitudes and beliefs after counseling increased sexual desire in women.

Using PLISSIT model in their study on women, with mastectomy, and their husbands, Faghani et al found that this model could improve the sexual function and the quality of life in the intervention group (34). The results of this study also match the results of our study in this regard.

Khakbazan et al compared the effect of cognitivebehavioral approach and PLISSIT-based counseling on the sexual function of women with multiple sclerosis and concluded that interventions based on this model, as well as cognitive-behavioral approaches improved sexual performance (35).

Likewise, Ayaz and Kubilay studied 60 patients with a stoma (i.e., ileostomy or colostomy due to colon cancer or ulcerative colitis) based on the PLISSIT model by conducting eight home visits and administering Sexual Satisfaction Questionnaire 6 weeks and 4 months after the intervention. The results of the study revealed that the mean scores of female sexual satisfaction improved by using this model. Moreover, the sexual function and its dimensions except for sexual pain significantly differed in the intervention group in comparison with the control group (36). The results of their study confirm the findings of the present study on the promotion of female sexual function after PLISSIT-based counseling. However, in the present study, the change in the mean scores of the pain was similar to that of the other variables, which was not in agreement with the results of the study by Ayaz and Kubilay in the intervention group. One of the reasons for such a difference between the results of these 2 studies is that the patients in Ayaz and Kubilay' study suffered from 
a stoma, which affected their sexual pain and both studies used a different instrument to measure the study variables.

Hosseini et al, using PRECEDE (Predisposing, Enabling, and Reinforcing Constructs), investigated 48 hysterectomized women during five 45-60-minute sessions. PRECEDE is an open-ended question-andresponse model for improving the sexual function with an influence on the behavior through changes in the attitude, knowledge, and beliefs. Based on their findings, this model significantly increased the female sexual function and their 6 sub-scales in the intervention group. The findings of this study are in good agreement with the results of our study as well (37).

Evaluating the mean scores of different sub-scales of sexual function (i.e., desire, arousal, lubrication, orgasm, satisfaction, and pain after the intervention) between intervention and control groups showed a statistically significant difference in all the above-mentioned studies $(24,32-37)$. Based on the findings of different studies performed so far, PLISSIT model has a positive effect in different societies.

According to a study, the majority of women declared that they had a greater willingness to discuss their sexual problems and function with female doctors and caregivers (38). Health care providers must have a better understanding of the impact of sexual function on a woman's life and provide more comprehensive care regarding sexual problems in their daily work (39), but most health professionals or health care providers speak with none of their clients about sexual relations due to the lack of time or sufficient information on sexual relations, as well as concerns about ethnic, racial, and cultural differences, educational and religious policies, and health care providers and clients attitudes (40).

The present research has some advantages. It included an appropriate sample size and excluded a small number of participants. In addition, this study was performed on nulliparous pregnant women aged 18-35 and the effects of pregnancy and age were adjusted accordingly. Further, the sexual function score was evaluated at baseline and then the study was conducted on pregnant women with sexual dysfunction. However, this study had some limitations as well. The follow-up period was relatively short and the researchers only relied on the health records and the participants' own statements in order to obtain some information about their mental health. It was also impossible to consult with the husbands, which could affect the results of the research. Therefore, other researchers are suggested to conduct further studies on pregnant women with sexual dysfunction in a long-term follow-up period during pregnancy.

\section{Conclusions}

Given the effect of PLISSIT-based sexual counseling on the improvement of the sexual function of pregnant women, this approach is recommended during pregnancy.
Furthermore, the results of this study can be applied for appropriate health planning and policy-making. Accordingly, preparing and developing better counseling, as well as educational and therapeutic programs can help gynecologists, midwives, psychologists, and health care workers in gynecologic clinics, specialized clinics for women, midwifery centers, health centers, psychiatric clinics, and family counseling centers. Therefore, it is recommended to investigate female sexual function and satisfaction when clients, especially pregnant women with sexual dysfunctions refer to health and counseling centers. If necessary, women should be given relevant information accordingly.

\section{Conflict of Interests}

Authors declare that they have no conflict of interests.

\section{Financial Support}

The Vice-chancellor of the Research and Technology of Tabriz University of Medical Sciences supported the study.

\section{Acknowledgments}

This paper is the result of an MSC thesis in midwifery counseling. The authors sincerely appreciate the Vicechancellor of the Research and Technology of Tabriz University of Medical Sciences for financial support, as well as Ardebil health centers and all the women who helped us with this study.

\section{References}

1. Liu HL, Hsu P, Chen KH. Sexual activity during pregnancy in Taiwan: a qualitative study. Sex Med. 2013;1(2):54-61. doi: $10.1002 / \mathrm{sm} 2.13$.

2. Loew N, Lehan Mackin M, Ayres L. Concept analysis of responsible sexual behavior in adult women. JOGNN. 2018;47(3):385-95. doi: 10.1016/j.jogn.2018.01.006.

3. Latham-Cork H, Porter C, Straw F. Sexual health in young people. J Paediatr Child Health. 2018;28(2):93-9. doi: 10.1016/j.paed.2017.11.003.

4. Lohman HL, Kobrin A. Addressing sexual activity of elders. In: Lohman HL, Byers-Connon S, Padilla RL, eds. Occupational Therapy with Elders. 4th ed. St. Louis, MO: Mosby; 2019: 156-69.

5. Thomas HN, Thurston RC. A biopsychosocial approach to women's sexual function and dysfunction at midlife: A narrative review. Maturitas. 2016;87:49-60. doi: 10.1016/j. maturitas.2016.02.009.

6. Yeniel AO, Petri E. Pregnancy, childbirth, and sexual function: perceptions and facts. Int Urogynecol J. 2014;25(1):5-14. doi: 10.1007/s00192-013-2118-7.

7. Babazadeh R, Najmabadi KM, Masomi Z. Changes in sexual desire and activity during pregnancy among women in Shahroud, Iran. INT J Gynaecol Obstet. 2013;120(1):82-4. doi: 10.1016/j.ijgo.2012.07.021.

8. Bouzouita I, Ellouze F, El Kefi H, et al. Sexuality of the Tunisian pregnant women: Facts between myth and reality. Sexologies. 2018;27(4):e103-e109. doi: 10.1016/j. sexol.2017.06.003.

9. Jamali S, Mosalanejad L. Sexual dysfnction in Iranian 
pregnant women. Iran J Reprod Med. 2013;11(6):479-86.

10. Tosun Guleroglu F, Gordeles Beser N. Evaluation of sexual functions of the pregnant women. J Sex Med. 2014;11(1):14653. doi: 10.1111/jsm.12347.

11. Staruch M, Kucharczyk A, Zawadzka K, Wielgos M, Szymusik I. Sexual activity during pregnancy. Neuro Endocrinol Lett. 2016;37(1):53-8.

12. Badri T, Maamri A, El Kissi Y. Impact of pregnancy on sexuality: a cross-sectional study of 100 tunisian women. Tunis Med. 2017;95(7):482-7.

13. Sagiv-Reiss DM, Birnbaum GE, Safir MP. Changes in sexual experiences and relationship quality during pregnancy. Arch Sex Behav. 2012;41(5):1241-51.doi: 10.1007/s10508011-9839-9.

14. Johnson CE. Sexual health during pregnancy and the postpartum. J Sex Med. 2011;8(5):1267-84. doi: 10.1111/j.1743-6109.2011.02223.x.

15. Woloski-Wruble AC, Oliel Y, Leefsma M, HochnerCelnikier D. Sexual activities, sexual and life satisfaction, and successful aging in women. J Sex Med. 2010;7(7):240110. doi: 10.1111/j.1743-6109.2010.01747.x.

16. Vannier SA, Rosen NO. Sexual Distress and Sexual Problems During Pregnancy: Associations With Sexual and Relationship Satisfaction. J Sex Med. 2017;14(3):387-95. doi: 10.1016/j.jsxm.2016.12.239.

17. Fok WY, Chan LY, Yuen PM. Sexual behavior and activity in Chinese pregnant women. Acta Obstet Gynecol Scand. 2005;84(10):934-8. doi: 10.1111/j.0001-6349.2005.00743.x.

18. MacPhedran SE. Sexual activity recommendations in high-risk pregnancies: what is the evidence? Sex Med Rev. 2018;6(3):343-57. doi: 10.1016/j.sxmr.2018.01.004.

19. Mercer B. Interviewing people with chronic illness about sexuality: an adaptation of the PLISSIT model. J Clin Nurs. 2008;17(11c):341-51. doi: 10.1111/j.13652702.2008.02582.x.

20. Yelton MM, Delfin NM. An Overview Of Sexuality. https:// core.ac.uk/download/pdf/48497921.pdf. Published 2015.

21. Perelman MA. The sexual tipping point: a mind/body model for sexual medicine. J Sex Med. 2009;6(3):629-32. doi: 10.1111/j.1743-6109.2008.01177.x.

22. Lee YM, Florez E, Tariman J, McCarter S, Riesche L. Factors related to sexual behaviors and sexual education programs for Asian-American adolescents. ANR. 2015;28(3):222-8. doi: 10.1016/j.apnr.2015.04.015.

23. Fakhri A, Pakpour AH, Burri A, Morshedi H, Zeidi IM. The Female Sexual Function Index: translation and validation of an Iranian version. J Sex Med. 2012;9(2):514-23. doi: 10.1111/j.1743-6109.2011.02553.x.

24. Rostamkhani F, Jafari F, Ozgoli G, Shakeri M. Addressing the sexual problems of Iranian women in a primary health care setting: A quasi-experimental study. Iran J Nurs Midwifery Res. 2015;20(1):139-46.

25. Annon JS. The PLISSIT model: A proposed conceptual scheme for the behavioral treatment of sexual problems. J Sex Educ Ther. 1976;2(1):1-15.

26. Fosnight A. Sexuality counseling for women's health providers. Physician assistant clinics. 2018;3(3):325-37. doi: 10.1016/j.cpha.2018.02.002.

27. Rosen RC. Assessment of female sexual dysfunction: review of validated methods. Fertil Steril. 2002;77(4):89-93.
28. Chang SR, Chen KH, Lin HH, Yu HJ. Comparison of overall sexual function, sexual intercourse/activity, sexual satisfaction, and sexual desire during the three trimesters of pregnancy and assessment of their determinants. J Sex Med. 2011;8(10):2859-67. doi: 10.1111/j.1743-6109.2011.02420.x.

29. Gałązka I, Drosdzol-Cop A, Naworska B, Czajkowska M, Skrzypulec-Plinta V. Changes in the sexual function during pregnancy. J Sex Med. 2015;12(2):445-54. doi: 10.1111/ jsm.12747.

30. Escudero-Rivas R, Carretero P, Caño Á, Cruz M, Florido J. Modifications of sexual activity during uncomplicated pregnancy: A prospective investigation of Spanish women. Health. 2013;5(8):1289.

31. Yildiz $\mathrm{H}$. The relation between prepregnancy sexuality and sexual function during pregnancy and the postpartum period: a prospective study. J Sex Marital Ther. 2015;41(1):4959. doi: 10.1080/0092623x.2013.811452.

32. Rutte A, van Oppen P, Nijpels G, et al. Effectiveness of a PLISSIT model intervention in patients with type 2 diabetes mellitus in primary care: design of a cluster-randomised controlled trial. BMC Fam Pract. 2015;16:1-9. doi: 10.1186/ s12875-015-0283-0.

33. Farnam F, Janghorbani M, Raisi F, Merghati-Khoei E. Compare the effectiveness of PLISSIT and sexual health models on women's sexual problems in Tehran, Iran: a randomized controlled trial. J Sex Med. 2014;11(11):267989. doi: 10.1111/jsm.12659.

34. Faghani S, Ghaffari F. Effects of sexual rehabilitation using the PLISSIT model on quality of sexual life and sexual functioning in post-mastectomy breast cancer survivors. APJCP. 2016;17(11):4845-51. doi: 10.22034/ apjcp.2016.17.11.4845.

35. Khakbazan Z, Daneshfar F, Behboodi-Moghadam Z, Nabavi SM, Ghasemzadeh S, Mehran A. The effectiveness of the permission, limited information, specific suggestions, intensive therapy (PLISSIT) model based sexual counseling on the sexual function of women with Multiple Sclerosis who are sexually active. Mult Scler Relat Disord. 2016;8:1139. doi: 10.1016/j.msard.2016.05.007.

36. Ayaz S, Kubilay G. Effectiveness of the PLISSIT model for solving the sexual problems of patients with stoma. J Clin Nurs. 2009;18(1):89-98. doi: 10.1111/j.13652702.2008.02282.x.

37. Hosseini N, Amini A, Alamdari A, Shams M, Vossoughi M, Bazarganipour F. Application of the PRECEDE model to improve sexual function among women with hysterectomy. INT J Gynaecol Obstet. 2016;132(2):229-33. doi: 10.1016/j. ijgo.2015.07.019.

38. Eldridge KF, Giraldi A. Communication about sexual matters with women attending a danish fertility clinic: a descriptive study. Sex Med. 2017;5(3):196-202. doi: 10.1016/j.esxm.2017.06.005.

39. Murtagh J. Female sexual function, dysfunction, and pregnancy: implications for practice. J Midwifery Womens Health. 2010;55(5):438-46. doi: 10.1016/j.jmwh.2009.12.006.

40. Dyer K, das Nair R. Why don't healthcare professionals talk about sex? A systematic review of recent qualitative studies conducted in the United kingdom. J Sex Med. 2013;10(11):2658-70. doi: 10.1111/j.17436109.2012.02856.x.

(c) 2019 The Author (s); This is an open-access article distributed under the terms of the Creative Commons Attribution License (http://creativecommons.org/licenses/by/4.0), which permits unrestricted use, distribution, and reproduction in any medium, provided the original work is properly cited. 